\title{
EXPERIMENTALLY VALIDATED NONLINEAR ANALYSIS OF BRIDGE PLATE GIRDERS WITH DEFORMATIONS
}

\author{
MIESZKO KUŻAWA, JAN BIEŃ \\ Wrocław University of Technology, Faculty of Civil Engineering, \\ Wybrzeże Wyspiańskiego 27, 50-370 Wrocław, Poland. E-mail: mieszko.kuzawa@pwr.edu.pl
}

\begin{abstract}
Comprehensive methodology of numerical nonlinear analysis of the consecutive phases in the structural behaviour of bridge plate girders with deformations is presented. The analysis concerns all stages of structure loading until failure and especially determination of the ultimate shear load capacity. Verification and validation of the numerical procedures proposed is based on comparison of the calculated results with effects of experimental laboratory shear capacity tests of plate girders carried out at the University of Ljubljana.
\end{abstract}

Key words: FEM analysis, experimental tests, bridge plate girders, deformations, load capacity

\section{INTRODUCTION}

In Poland, steel girder spans constitute about 50\% of the total number of railway bridge spans and $20 \%$ of the total number of road bridge spans. The most popular structural solutions used in railway bridges are steel spans made of: plate girders (about 28\%), lattice girders $(10 \%)$, and rolled girders (over $4 \%$ ).

The oldest, still existing, railway bridges were built at the beginning of the 19th century. The intensive development of the railway system started at the end of the 1930s and the beginning of the 1940s. This means that a substantial number of the railway civil engineering structures operated in Poland are advanced in years. Nearly $45 \%$ of the railway structures (about 8000 units) are almost 100 years old and only about $15 \%$ of them are less than 40 years old. A similar situation is in the whole Europe (Sustainable Bridges [11]).

Because of the old age of the steel spans of the railway bridges their condition keeps deteriorating, mainly due to the increasing damage to their structural members. The damage, being the natural consequence of inevitable degradation processes, weakens the structures, leading to their operation in conditions not foreseen in the design, whereby limitations on their operation have to be imposed (e.g., Bień [2], [3]; Maksymowicz et al. [9]; Helmerich and Bień [7]).

There are not many works on the precise analysis of structural behaviour of bridges and its elements with defects. In particular, there is lack of a precise methodology for determination of the load capacity of railway bridges made of plate girders taking into account the presence of typical defects occurring during operation.

Therefore, a comprehensive methodology, based on the finite element method (FEM), for the modelling and nonlinear analysis of plate girder spans, taking into account deformations, is proposed in this paper. The damage considered can arise in the course of: the production of the material, the prefabrication of the components and the construction and operation of the bridge. In order to verify the numerical procedures of a proposed methodology for the nonlinear analysis and assessment of the ultimate shear capacity of bridge plate girders the theoretically determined values are compared with the results of experimental laboratory shear capacity tests of plate girders carried out at the University of Ljubljana (Sinur [10]).

\section{METHODOLOGY OF ANALYSES}

\subsection{PROCEDURES OF ANALYSES}

A comprehensive analysis of the behaviour of damaged bridge plate girders in the consecutive stages of their loading until failure, especially the determination of their ultimate load capacity, is not an easy task. Because of local stability loss, the redistribution of 
internal forces in girder cross sections and the influence of these phenomena on the global stability of the structure it is necessary to solve the stability and postbuckling state problem, which is nonlinear in both the physical and geometrical sense. Simulations should take into account many peculiarities occurring in thinwalled structures, such as: geometric, structural and technological imperfections, the possible interaction between different forms of buckling, shear lag, nonlinear dependences between strains and displacements and nonlinear constitutive material dependences. Hence a study of the response of the structure to loading in the consecutive phases, including the precise determina- tion of the ultimate load capacity of the bridge plate girder modelled as a discrete system, requires a sequence of numerical analyses carried out using the finite element method (FEM).

General procedures for analyzing plate girders in the particular phases of loading until failure and procedures for assessing the ultimate shear capacity on the basis of the results obtained using a sequence of various FEM analyses are proposed below. The theoretical procedures are applicable to plate girder analyses using two- and three-dimensional finite elements in three-dimensional space, i.e., $\left(e^{2}, s^{3}\right),\left(e^{3}, s^{3}\right)$ and $\left(e^{2}+e^{3}, s^{3}\right)$ class models, capable of taking into ac-

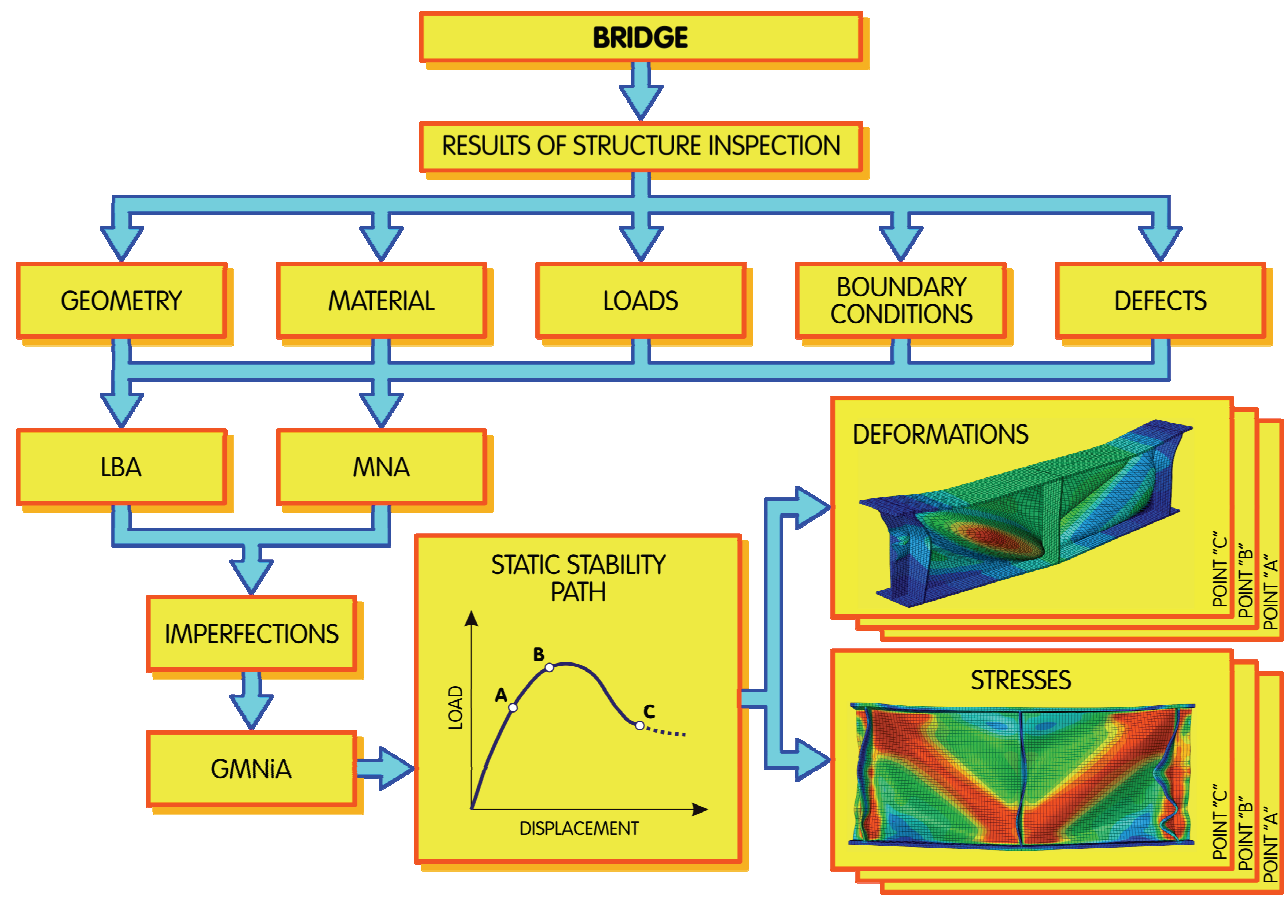

Fig. 1. Flow chart of nonlinear FEM analyses of bridge plate girders with defects, in consecutive phases of girder behaviour until failure (Kużawa [8])
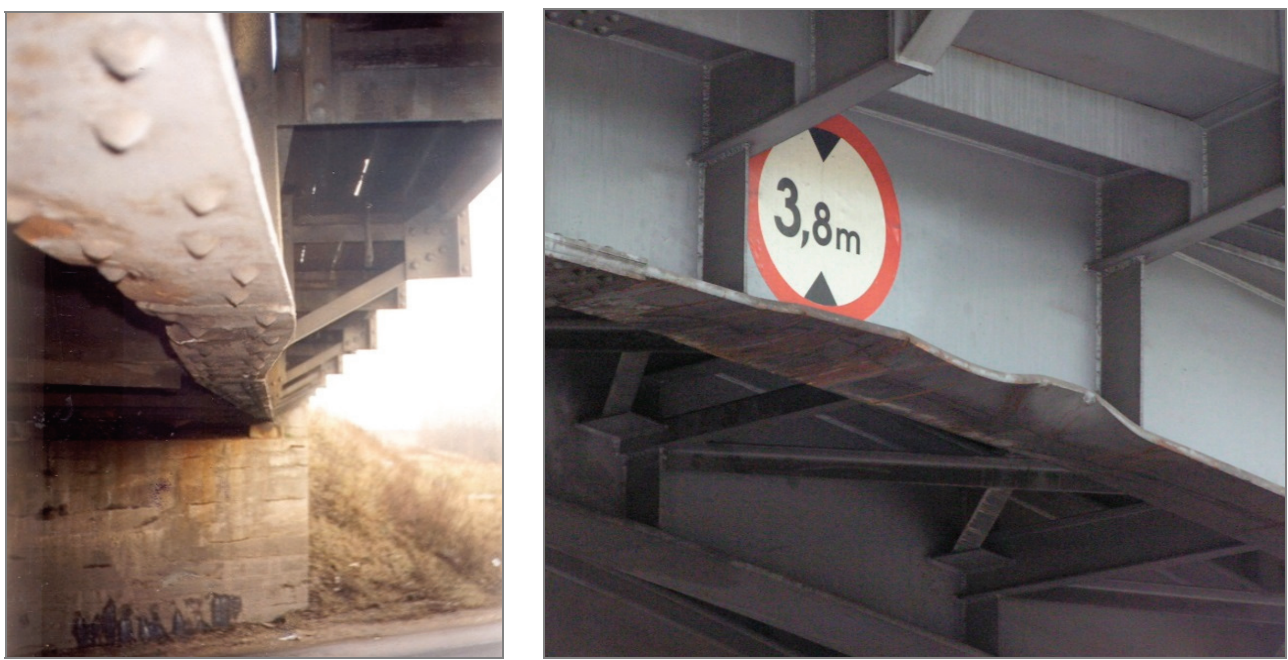

Fig. 2. Deformations of bridge plate girders 
count the peculiarities occurring in thin-walled structures.

The proposed general procedure for nonlinear FEM analyses of plate girders in the consecutive phases of their behaviour until failure is shown in Fig. 1. The procedure covers an analysis of structural damage in the form of deformations of girder components. This kind of damage to bridge plate girders (Fig. 2) often arises during their prefabrication and construction and as a result of vehicle impacts in the course of bridge service life.

The proposed methodology involves the following analyses (Fig. 1):

- The linear buckling analysis (LBA), used to determine eigenvalues (critical loads and the form of buckling), based on the bending theory of thinwalled elements and the small deflection theory, assuming linear elastic material properties.

- The geometrically and materially nonlinear analysis (GMNA), using the bending theory of thinwalled elements with ideal geometry and large deflections, based on the nonlinear elastic-plastic material characteristic.

- The geometrically and materially nonlinear analysis with imperfections (GMNIA), based on the large deflection theory and the nonlinear elasticplastic material characteristic, which explicitly takes into account geometric imperfections in the form of unintended deviations of the shape of the thin-walled element central surface. Imperfections may also reflect deviations from the boundary conditions and internal stresses. The bifurcation stability of structural members is checked at each load level.

Using the proposed methodology and a sequence of the FEM analyses, bridge plate girders are analyzed in the consecutive phases of their behaviour: the linear elastic phase, the postbuckling (nonlinear elastic or/and elastic-plastic) phase, the ultimate load capacity phase and the failure phase. The main results of the analyses are static stability paths (SSP) for the whole structural system, deformations and stresses calculated at particular points of the girder computational model in all the stages of loading.

A flow chart of the proposed procedure for assessing the ultimate shear capacity of plate girders with deformations $R_{u}$, based on the results of various FEM analyses (especially GMNIA), is shown in Fig. 3. The ultimate bending load capacity of a structure is defined as the maximum load with a specific scheme of action on the structure as a result of which the latter loses its ability to carry the load and becomes a geometrically unstable system.

As shown in detail in Kużawa [8], bridge plate girders are structures which as regards ultimate load are moderately sensitive to the diversity of forms of geometric imperfections (differences in ultimate load for different forms usually do not exceed $5 \%$ ). Therefore, it is proposed to assess the ultimate shear capacity of plate girders in the following way:

- first, the static linear eigenvalue problem should be solved (LBA) to determine critical buckling

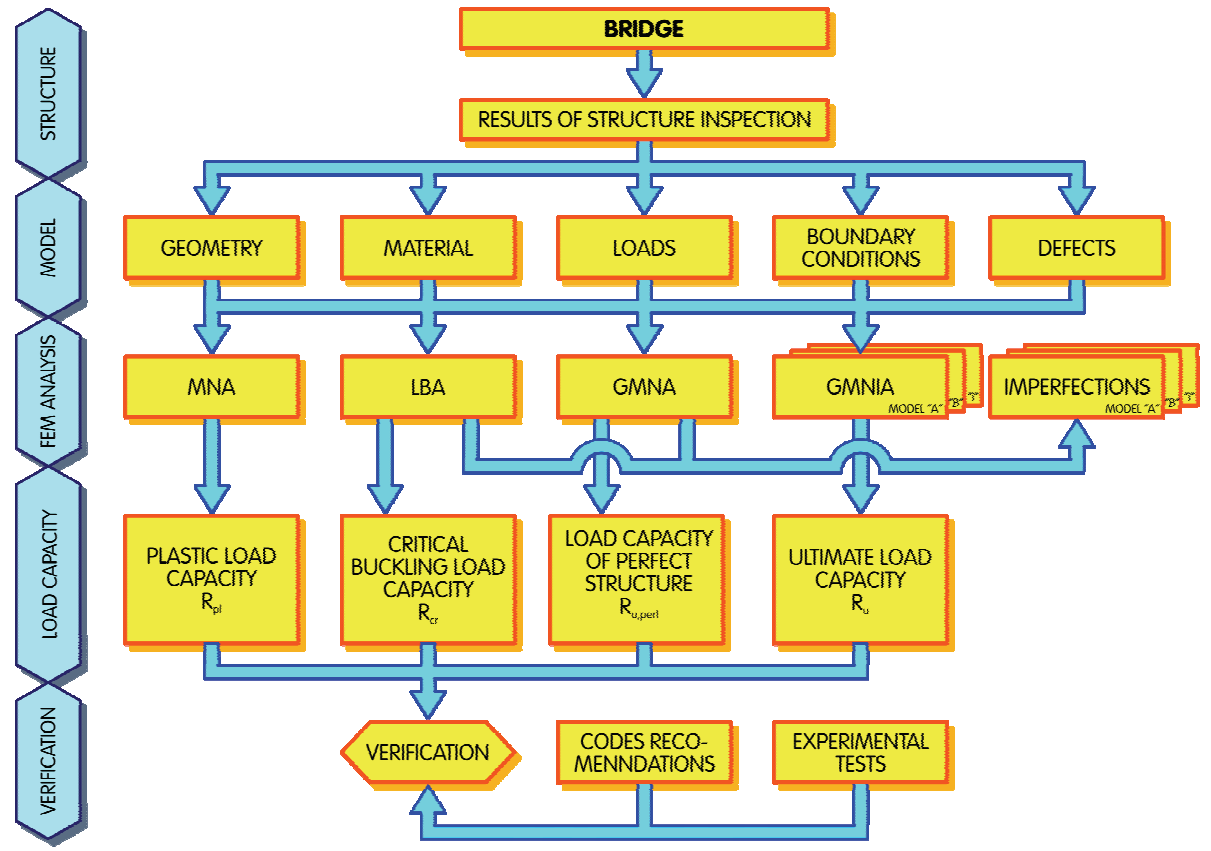

Fig. 3. Procedure for assessing ultimate shear capacity of plate girders with initial defects, using full GMNIA (Kużawa [8]) 
load capacities $R_{c r}$ and the corresponding forms of buckling, with possible damage taken into account;

- the results obtained from the LBA should be used to disturb the finite element mesh in a subsequent GMNIA; the initial deformations of the girder components are modelled as having a shape similar to the basic buckling form or to a linear combination of many forms, or consistently with the EN 1993-1-5 [6] standard recommendations;

- a GMNIA should be carried out using the scheme of kinematic excitation in a given cross section, whereby the ultimate load capacity of the structure and the behaviour of the latter until failure can be determined;

- the results of the analyses should be verified through calculations done in accordance with EN 1993-1-5 [6], on the basis of analytical results for similar structures and/or the results of materially nonlinear analyses (MNA).

\subsection{GEOMETRY MODELS AND FINITE ELEMENTS}

In most cases, numerical FE models for analyzing the stability and ultimate load capacity of plate girders are built from four-node shell elements with six degrees of freedom in each element (Chrościelewski et al. [5]; Zienkiewicz and Taylor [13], [14]) since such elements are particularly suitable for computing shells with irregular geometry.

The loading of such systems is characterized by the occurrence of a deformation corresponding to the almost stiff displacement of large fragments of the structure. Then in FEM analyses there is a strong tendency towards shear locking at full integration and towards parasitic deformations (spurious zero-energy modes, hourglassing) in the case of reduced integration (Braes [4]; Chrościelewski et al. [5]; Abaqus [1]; Witkowski [12]).

In the author's opinion, taking into account the theoretical results reported in Kużawa [8], models constructed from two-dimensional 4-node rectangular shell elements with the linear interpolation of deformations inside the element and with one integration point (e.g., the S4R elements in Abaqus) ensure the most effective solutions to the problems considered in this paper. The results obtained using such elements are reported as part of the comparative theoretical/experimental analyses presented further in this paper.

\subsection{NONLINEAR ANALYSIS ALGORITHM AND MODELLING \\ OF BOUNDARY CONDITIONS AND LOADS}

A typical scheme of computing plate girder model boundary conditions is shown in Fig. 4, where for a two-panel girder the load (in the form of a kinematic excitation) and the symbols representing the geometric parameters of its components are graphically illustrated. The boundary conditions for the other models analyzed using GMNIA are similar. The models analyzed here are subjected to kinematic excitations (defined at a reference point) causing a uniform displacement of the whole girder cross section, which in most cases is located in the middle of the girder span. The aim is to generate a stress distribution approximating the pure shear in the linear elastic behaviour phase, in the web panels. Kinematic excitations are effected using interactive elements of the Coupling type offered by, e.g., Abaqus [1] and analyses are carried out by the iteration method using the NewtonRaphson algorithm.
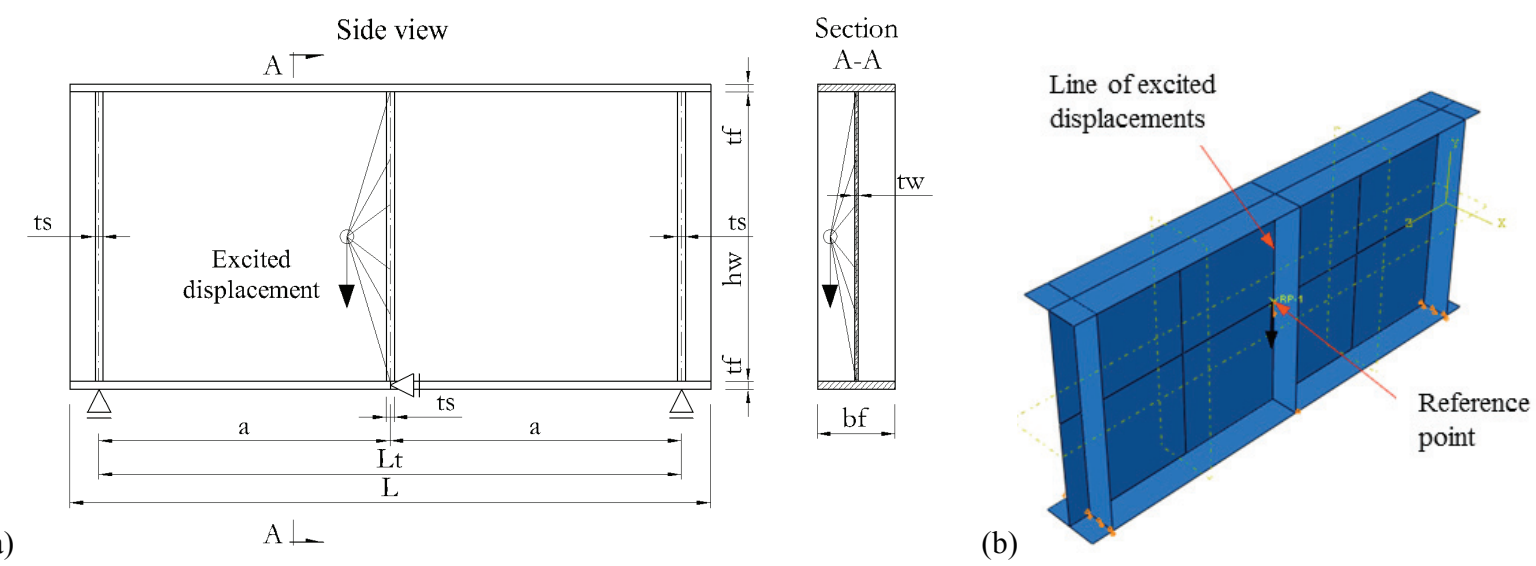

Fig. 4. Boundary conditions and geometric parameters of girder and graphic illustration of kinematic excitation 
In the successive steps of the iteration the value of the kinematic excitation is gradually increased up to a set value, which in the analyses carried out here usually did not exceed $20-30 \mathrm{~cm}$ because of the peculiar shape of the analyzed structures. The gradually increased displacement of the reference point is a kind of load. In the course of kinematic excitation a reaction arises at the reference point (node). The value of this reaction is a measure of the structure's ability to carry loads in a given state of its deformation. Thanks to this the particular phases in the behaviour of the structure up to the ultimate load capacity (since this moment the load keeps increasing) and also at failure (since this moment the load capacity of the structure decreases) can be analyzed. In the light of the analyses carried out in Kużawa [8] this solution is more effective than the algorithm controlled by the static stability path parameter (iteration by the arc-length method - a modification of the Newton-Raphson method).

The maximum reaction in the reference node (point) during kinematic excitation is called here the ultimate load capacity of a girder/span and its value is referred to as the ultimate load.

\subsection{MATERIAL MODELS}

The way of modelling the structural material is different depending on the type of analysis. In linear problems, e.g. the eigenvalue problem (LBA), it is enough to adopt elastic material constants. Since for the needs of such analyses steel is assumed to be a homogenous isotropic material, in the case of linear elastic problems one should determine two material constants: the elastic modulus (Young's modulus) $E=205 \mathrm{GPa}$ and Poisson's ratio $v=0.3$.

In the MNA, GMNA and GMNIA carried out an elastic-plastic model of material with isotropic hardening was used. The effects connected with the strain rate (viscosity) and with the kinematic hardening (particularly when modelling the unloading of a permanently deformed structure followed by the loading of the latter) were not taken into account.

In the general case, except for the numerical representation of real experiments, it is recommended to adopt a bilinear material model consisting of two segments differing in their angle of inclination to axis $\varepsilon$. One segment represents the elastic range and the tangent of the angle of inclination to axis $\varepsilon$ for this segment is equal to modulus $E$ which amounts to 205 GPA. The other segment represents a plasticized material and the tangent of the angle of inclination to axis $\varepsilon$ is equal to the value of tangent modulus $E_{T}$. The point of intersection of the segments demarcates plastic limit $f_{y}$. Tangent modulus $E_{T}=1 / 100 E$ was adopted. This value enables one to estimate bottom-up the ultimate load capacity in the case of plastic hinges and the kinematic mechanism, but one should take into consideration that in the case of materials with a wide plastic range (high $f_{u} / f_{y}$ ), the ultimate load capacity is bound with a higher failure energy (by about $1-1.5 \%)$

The Huber-Mises plastic flow criteria were applied to solve the problems with material nonlinearity taken into account.

\section{EXPERIMENTAL VERIFICATION OF NUMERICAL PROCEDURES FOR DETERMINING ULTIMATE LOAD CAPACITY OF PLATE GIRDERS}

\subsection{INTRODUCTION}

The proposed methodology for numerical analyses was experimentally verified on the basis of the results of plate girder ultimate load capacity tests carried out in the laboratory of the University of Ljubljana, described in detail in Sinur [10]. The structures tested were shaped so that they would fail as a result of high shear and/or the interaction of shearing forces and bending moments.

In order to verify the proposed methodology for theoretical numerical analyses of plate girders the experimental results for selected phases in the behaviour of the structures were compared with the results of theoretical analyses carried out by the authors. The comprehensive verification covered the theoretical procedures, the way of modelling the structure, the choice of finite elements, the taking into account of the effects of geometric, structural and construction imperfections, the assumptions concerning (support) boundary conditions, the load model, the material model and the adopted computing algorithms.

\subsection{ANALYSIS OF PLATE GIRDERS IN NONLINEAR PHASES OF THEIR BEHAVIOUR}

The structure considered (Fig. 5) was shaped and loaded in such a way that transverse forces and bending moments predominated and their interaction 
(a)
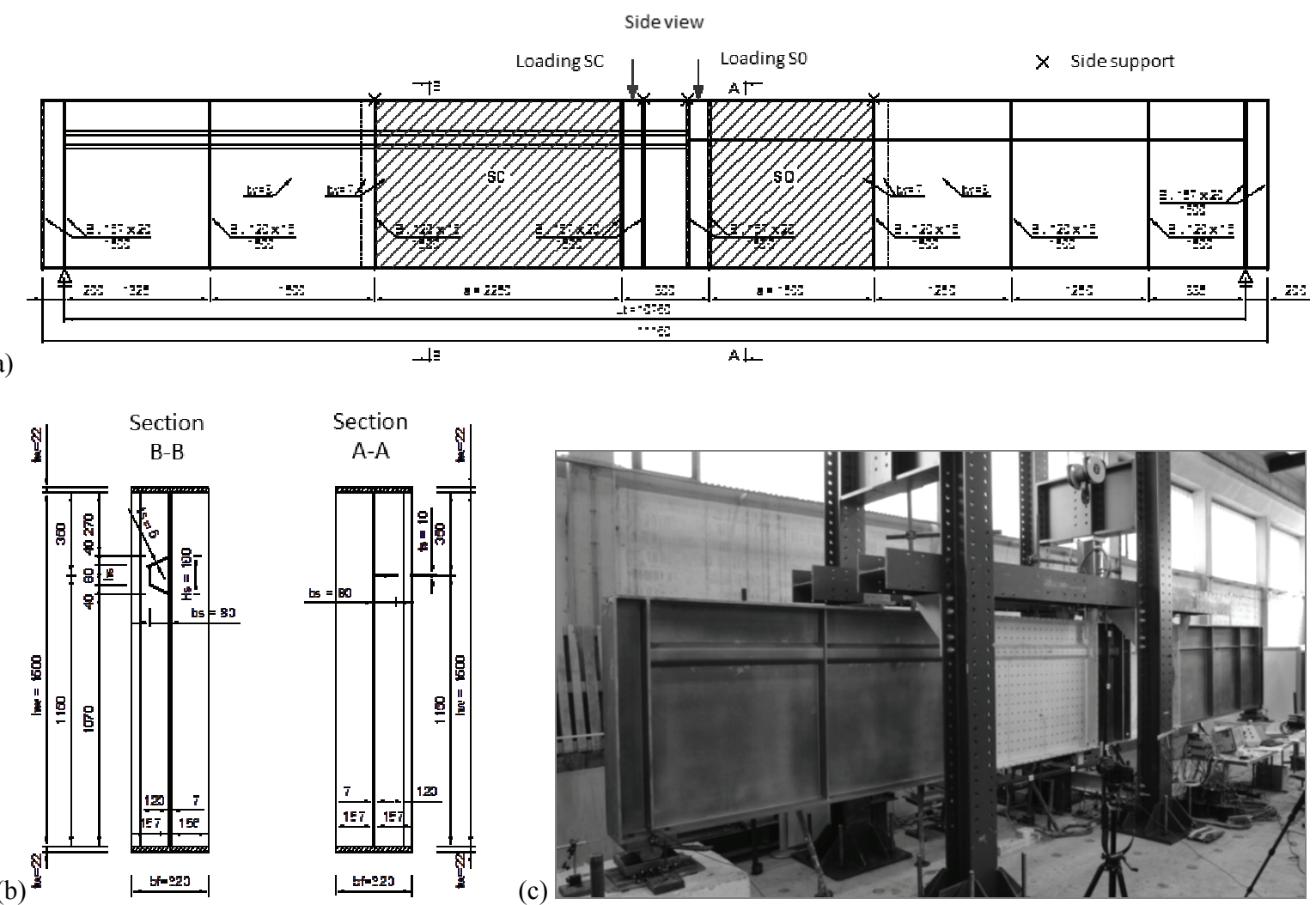

(c)

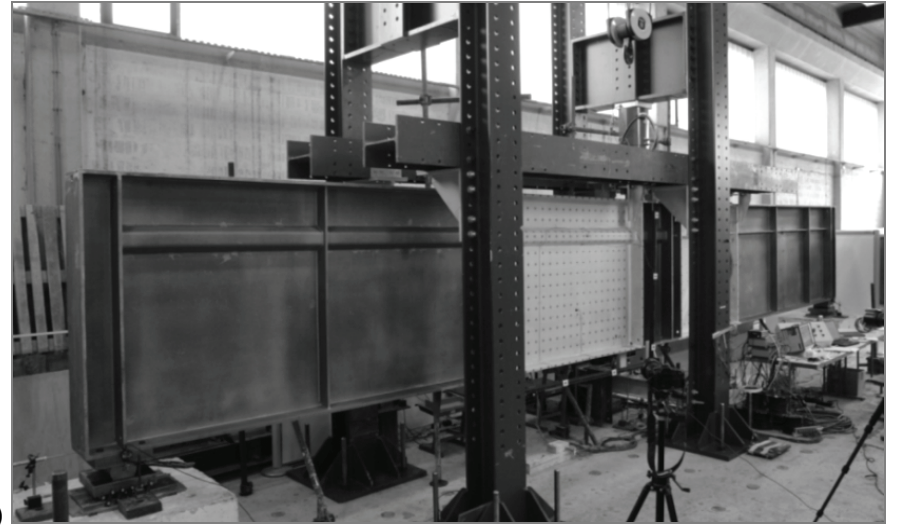

Fig. 5. Test stand and basic dimensions of analyzed girder (Sinur [10])

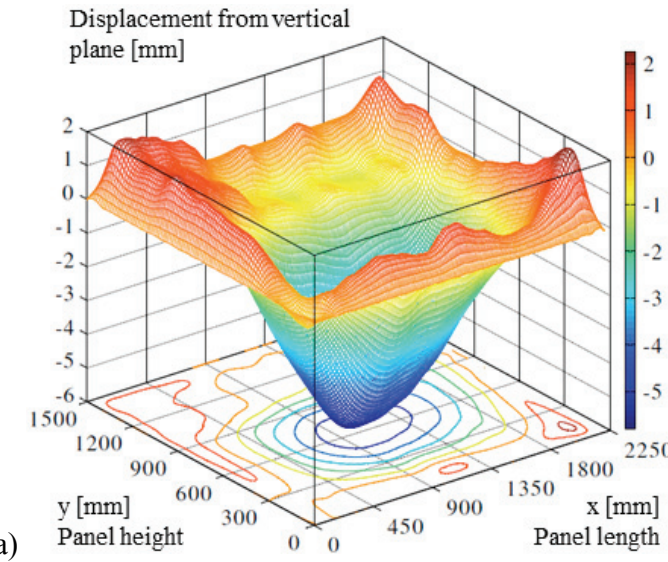

(b)

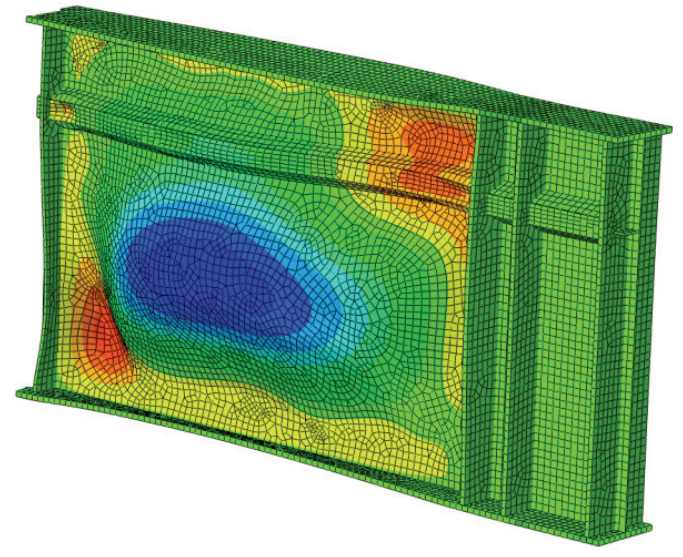

Fig. 6. Geometric imperfections (deformations) of panel SC:

(a) measured values (Sinur [10]), (b) discretization and deformations calculated in computational model created by the authors

would result in failure. Deformations within selected panels (SC and S0) were analyzed in the particular phases of loading.

The test stand and its schematic are shown in Fig. 5. Panels S0 and SC (Fig. 5) were tested within one girder. First, panel S0 was tested (load capacity is exhausted within panel $\mathrm{S} 0$ ), then the girder geometry was restored to almost the original form and a diagonal element was installed in panel S0, which significantly increased the buckling load capacity of the latter. The measures made it possible to test panel SC (load capacity is exhausted within panel SC, see the load for SC in Fig. 5).

The plate girder was made of steel S 335. From a hydraulic actuator the load would be transmitted to the girder top flange in the place where its transverse braces are located. The full loading of the girder was effected in about 10 phases. During the tests deformations, displacements within panels SC and S0 and the loading forces were continuously measured. The measured de- 
formation values for the $\mathrm{SC}$ test are presented in Fig. 6a, while the discretization in the computational model is shown in Fig. 6b. The measured geometric imperfection values for the S0 test are presented in Fig. 7a, while the discrete computational model is shown in Fig. $7 \mathrm{~b}$.

The structure tested was mapped using a class $e^{2}, p^{3}$ geometry model, i.e., a model consisting of twodimensional elements $\left(e^{2}\right)$ situated in three-dimensional space $\left(s^{3}\right)$ and the numerical analyses were carried out using the Abaqus [1] system consistently with the principles presented in Section 2. The basic data on the structure model and the adopted computing algorithms are as follows:

- the model consists of 4-node two-dimensional S4R finite elements with reduced integration; its grid size is $25 \mathrm{~mm} \times 25 \mathrm{~mm}$;

- the large displacement and small deformation (geometric nonlinearity) theory applies;

- a multilinear isotropic elastic-plastic material (material nonlinearity), whose characteristics were determined on the basis of the strength tests presented in Sinur [10], was used;

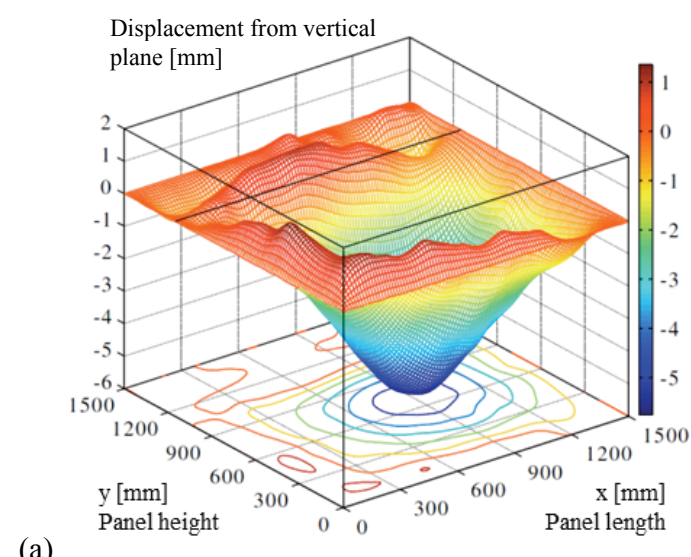

(b)

Fig. 7. Deformations of panel S0:

(a) measured values (Sinur [10]), (b) discretization and deformations calculated in computational model created by the authors

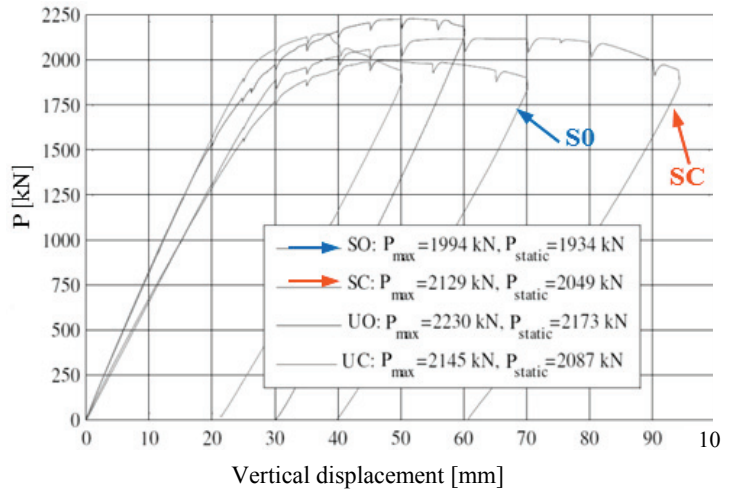

Fig. 8. Static stability paths (SSP): (a) experimental results (Sinur [10]),

(b) results of numerical analyses carried out by the authors
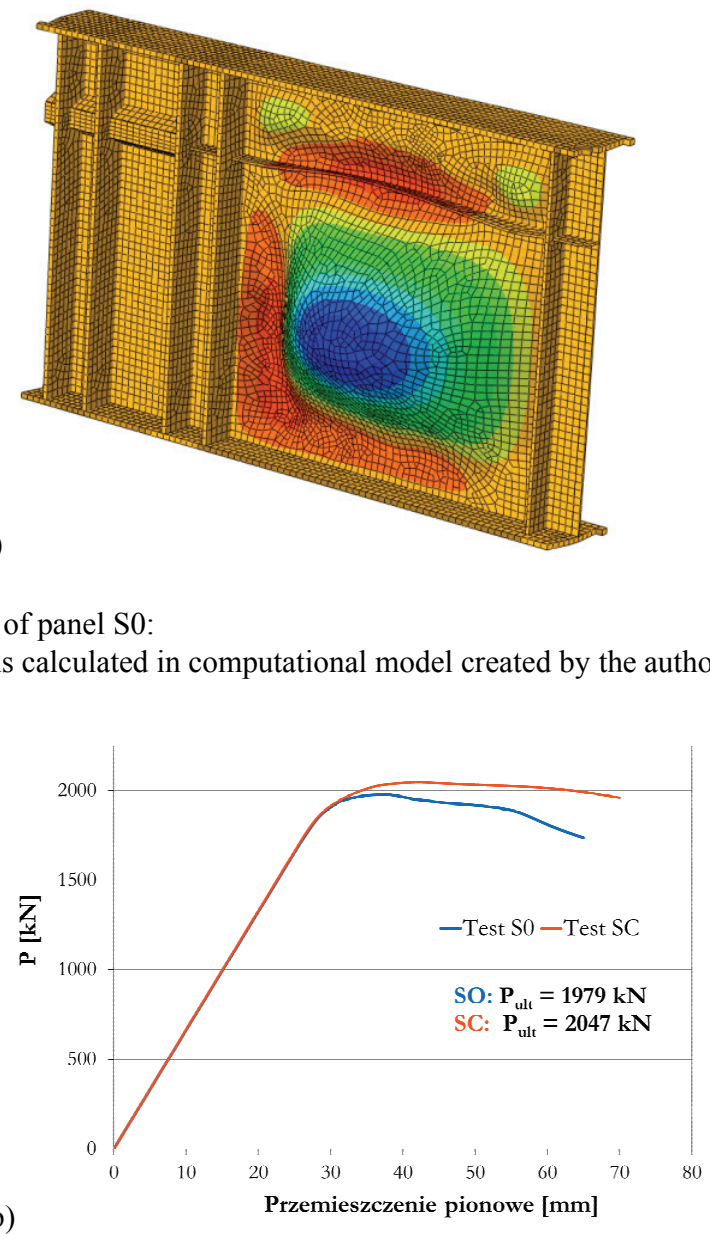

- the Huber-Mises material plastic flow criterion was adopted;

- a Coupling interaction (Abaqus [1]) was used to effect kinematic excitations;

the response of the structure in the particular loading steps was calculated using the NewtonRaphson algorithm.

The experimental static stability paths (SSP) and the ones determined by the authors through numerical analyses in accordance with the proposed methodology are compared in Fig. 8. There is good agreement between the respective results. In the case of the S0 test, the experimental ultimate load (static value $P_{\text {ult }}=1934 \mathrm{kN}$ ) is by $2.3 \%$ lower than the calculated one $\left(P_{\text {ult }}=1979 \mathrm{kN}\right)$. In the case of the SC tests, the experimental ultimate load (static value $\left.P_{\text {ult }}=2049 \mathrm{kN}\right)$ is by $0.1 \%$ higher than the calculated one $\left(P_{\text {ult }}=2047 \mathrm{kN}\right)$.

Figures 9 and 10 show maps of displacements perpendicular to the central plane of the web respectively in panel SC and S0 in the failure phase. The character of the displacements measured in the particular areas

(b) 
(a)

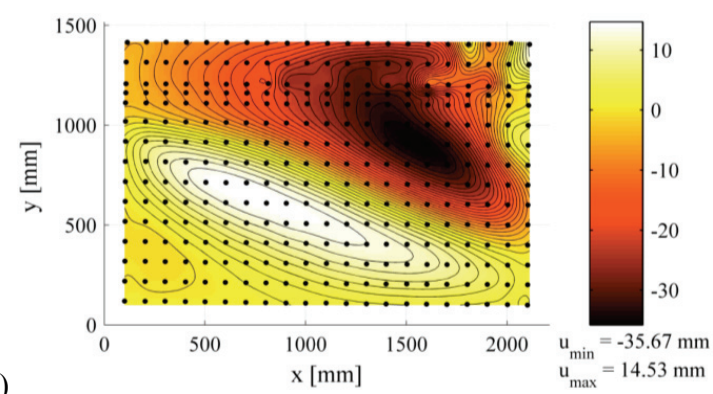

(b)

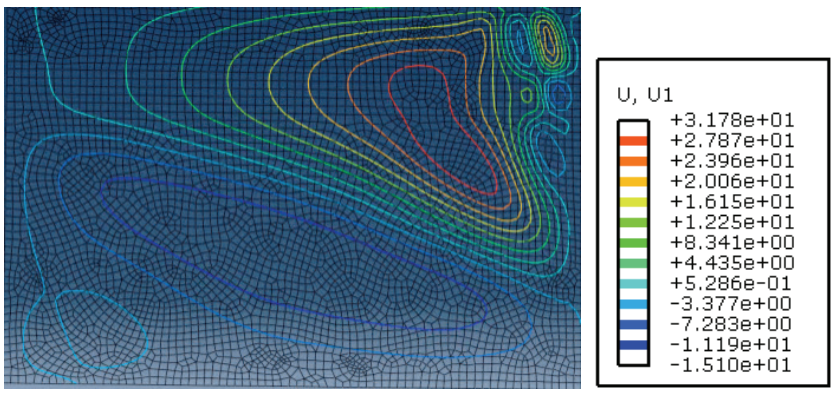

Fig. 9. Displacements perpendicular to central plane of web in panel SC (test SC), at maximum vertical displacement $\mathrm{U} 2=70 \mathrm{~mm}$ : (a) measured values (Sinur [10]), (b) values calculated by the authors

(a)

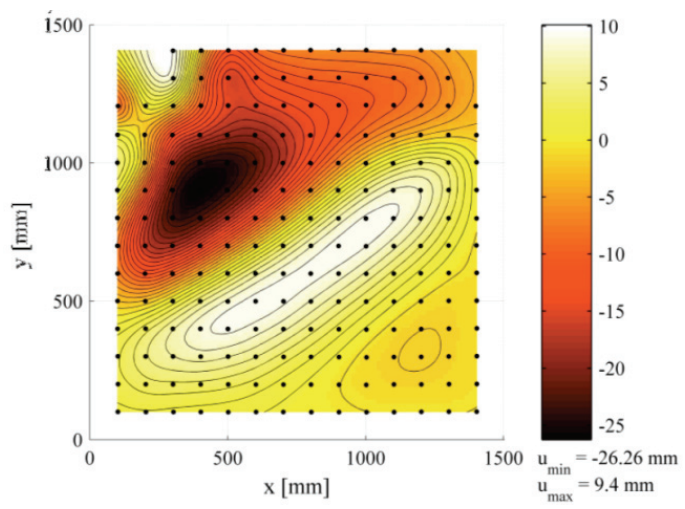

(b)

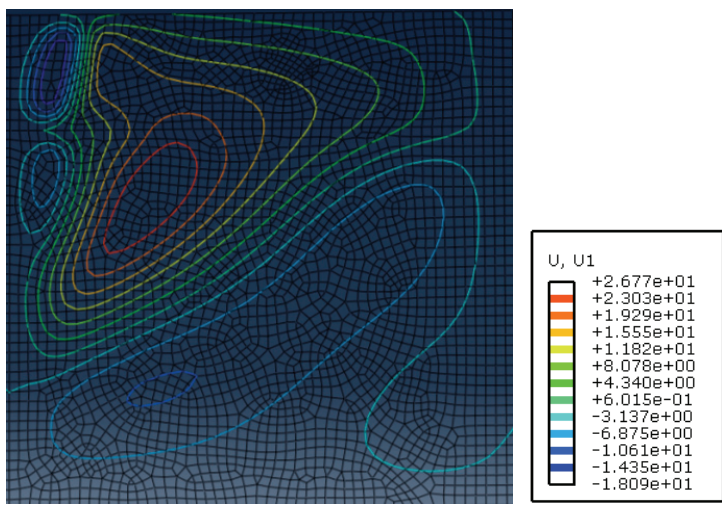

Fig. 10. Displacements [mm] perpendicular to central plane of web in panel $\mathrm{S} 0$ (test $\mathrm{S} 0$ ) at maximum vertical displacement $\mathrm{U} 2=55 \mathrm{~mm}$ : (a) measured values (Sinur [10]), (b) calculated values

of the panels (Fig. 9a and Fig. 10a) is highly consistent with the results of the numerical analyses (Fig. 9b and Fig. 10b, respectively). The largest differences between the two sets of results occurred at low values of the displacements perpendicular to the vertical plane, i.e., in the elastic phase of the structure behaviour, in which the deformations to a large extent depend on the shape and values of the initial deformations. Whereas the calculated deformations within the panels show good agreement with the deformations measured in the elastic-plastic state and the plastic state and in the failure phase (after the ultimate load is exceeded). The failure mechanism is due to both high bending within the analyzed panel (as indicated by the local bucklings within the upper subpanel) and high shear (as indicated by the well formed diagonal tension field in the bottom subpanel.

\section{CONCLUSION}

A comprehensive methodology, based on the finite element method (FEM), for the modelling and nonlinear analysis of bridge plate girders with damage in the form of deformations was presented. The results of plate girder ultimate load capacity tests carried out in the Laboratory of the University of Ljubljana (Sinur [10]) were used to verify the results of the theoretical analyses.

The proposed procedures were validated by good agreement between the experimental and theoretical results for all the phases of loading until failure. This particularly applies to the methodology for determining the ultimate load capacity of bridge plate girders: the way of modelling the structure, the choice of finite elements, the fact of taking into account the effects of initial defects (imperfections) of girders, the assumptions concerning (support) boundary conditions, the load model, the material model and the adopted computing algorithms.

The comparisons of the results of the experimental and theoretical studies show that the methodology proposed enables the effective analysis of the behaviour of plate girders under shear and in the case of bending and shear interaction, with damage in the form of structural deformations being taken into account, in its consecutive phases until failure. The best agreement between the calculated values and the measured ones was obtained for the range of loading 
force P [kN] (see Fig. 8) in the particular phases of girder behaviour, estimated using static stability paths. Good agreement was also obtained between the calculated and measured deformations within the analyzed girder panels, despite the fact that the deformations of the structure's members to a large extent depend on the shape and values of the initial deformations (Kużawa [8]), which means that the precision of mapping the deformations had a decisive influence on the results obtained.

In the authors' opinion the proposed theoretical methodology is likely to find application in nonlinear analyses of the behaviour of various plate girders, and particularly in procedures for estimating the shear capacity of existing structures with damage in the form of excessive deformations.

Scientific research has been carried out as a continuation of the Project "Innovative recourses and effective methods of safety improvement and durability of buildings and transport infrastructure in the sustainable development" financed by the European Union from the European Fund of Regional Development based on the Operational Program of the Innovative Economy.

\section{REFERENCES}

[1] Abaqus, Abaqus Online Documentation: Version 6.10-EF2, IDS Dassault Systèmes, 2010.

[2] BIEŃ J., Damage to and diagnosis of bridges, WKŁ, Warsaw 2010, (in Polish).

[3] BIEŃ J., Modelling of structure geometry in Bridge Management Systems, Archives of Civil and Mechanical Engineering, Vol. XI, No. 3, 2011, 519-532.
[4] Braes D., Finite Elemente. Theorie, schnelle Löser and Anwendungen in der Elastizitatstheorie, Springer, Berlin 1992.

[5] Chrościelewski J., Makowski J., Pietraszkiewicz W., Statics and dynamics of multi-plate shells; Nonlinear finite element theory and method, Wydawnictwo Instytutu Podstawowych Problemów Techniki PAN, 2004, (in Polish).

[6] EN 1993-1-5, Eurocode 3, Design of steel structures - Part 1-5, Plated structural elements, European Committee for Standardization, Brussels 2008.

[7] Helmerich R., BieŃ J., 100 Jahre Kaiser/GrunwaldzkiBrücke in Wroctaw (Polen), Stahlbau, Vol. 81, No. 2, 2012, 156-159.

[8] KuŻAwA M., Ultimate shear capacity of bridge plate girders with influence of damage taken into account, Doctoral thesis, Reports of the Institute of Civil Engineering at Wrocław University of Technology, No. PRE-1/2013.

[9] Maksymowicz M., Cruz P., BieŃ J., Load capacity of damaged $R C$ slab spans of railway-bridges, Archives of Civil and Mechanical Engineering, Vol. XI, No. 4, 2011, 963-978.

[10] SINUR F., Behaviour of longitudinally stiffened plate girders subjected to bending-shear interaction, Doctoral Thesis, Faculty of Civil and Geodetic Engineering, University of Ljubljana, Ljubljana 2011.

[11] Sustainable Bridges (2007), Guideline for Load and Resistance Assessment of Railway Bridges, Integrated Research Project "Sustainable Bridges - Assessment for Future Traffic Demands and Longer Lives", www.sustainablebridges.net (04.04.2015 r.).

[12] WitKowSKI W., Synthesis of the formulation of nonlinear mechanics of shells subject to finite rotations in terms of FEM, (in Polish), Monograph 111, Gdańsk University of Technology Publishing House, Gdańsk 2011.

[13] ZiEnKIEWICZ O.C., TAYLOR R.L., The Finite Element Method - Its basis and fundamentals, 6th ed., 4th repr., Elsevier Butterworth-Heinemann, Amsterdam 2006a.

[14] ZIENKIEwICZ O.C., TAYLOR R.L., The Finite Element Method - Solid Mechanics, 6th ed., 4th repr., Elsevier ButterworthHeinemann, Amsterdam 2006b. 